microwaves as a means of non-destructive testing. Unfortunately the method is not applicable to conductors, but can be used for materials such as rubber. Dr J. M. Burch of the National Physical Laboratory gave the most accomplished presentation at the conference, describing the use of holography in surface inspection. If two holograms of a surface, taken before and after changes in shape have occurred, are superimposed on the same plate, the result is an interference pattern which provides information about the change in shape. This method may be too accurate for industrial use, as it cannot easily be used for relatively crude changes in topology or for unpolished surfaces.

The last morning of the conference was devoted to the problems of making innovation pay. Dr H. M. Finniston said that the problems of sales, labour relations and finance were much the most important, and Mr D. N. King of the National Research Development Corporation explained what NRDC was doing about it. Dr Finniston, a member of the board of NRDC, was not above criticizing it-expenditure of $£ 25$ million in 18 years in an economy where research expenditure was now $£ 1,000$ million a year was neither much of a primer nor much of a pump, he thought. Although the discussion tended to dissolve into generalities, it showed that there is still a long way to go before industry and government establishments see problems from a common viewpoint. It is, of course, arguable whether this is a desirable aim; right at the start of the conference, Sir Nevill Mott said that if the ministry was really looking for a payoff from research in three years, it was being shortsighted.

\section{Communication between Cells}

\section{from a Correspondent in Cell Biology}

Normal tissue growth requires that cells should recognize each other and stop growing or moving at the right time and place. Understanding how this regulation is achieved is of fundamental importance. $A$ priori one might expect that some kind of chemical signal passes from cell to cell. This is certainly the simplest explanation of the phenomenon of contact inhibition-cells stop moving and dividing when they come into contact with each other. The work of Loewenstein and his collaborators is particularly pertinent. They have shown that at regions of cell contact, junctional surfaces, in several tissues cellular substances diffuse rather freely from the interior of one cell to that of the next. In dipteran salivary gland cells, for example (Kanno and Loewenstein, Nature, 212, 629; 1966), molecules of molecular weight up to about $10^{3}$ and $10^{4}$ can cross junctional surface membranes. Thus a quite large molecule could act as a signal for contact inhibition. Until such specific signal molecules have been identified, however, this hypothesis cannot be tested directly. Nevertheless it is possible to compare cellular intercommunication in normal cells inhibited by contact and in cancer cells which have uncontrolled growth, and also in cancer cells and normally growing cells.

Loewenstein and his collaborators have now done this (Loewenstein and Kanno, J. Cell. Biol., 33, 225; 1967, and Loewenstein and Penn, ibid., p. 235). They chose an electrical test for cellular intercommunication. A current of ions is injected through a microelectrode into a cell and the resulting membrane voltage across the membrane of the impaled cell and adjacent cells is measured. A considerable fraction of the current injected into a normal rat liver cell passes to adjacent cells. For practical purposes, the parenchymal cells of liver are interconnected and form a functional continuum at least as far as part of their ionic content is concerned. Cancerous liver cells, however, have no detectable ionic intercommunication; they behave as discrete units. Furthermore, histologically normal cells neighbouring a cancer cell have reduced ionic communication. Both slow and fast growing cancers induce this change in normal cells. The implication is that in a cell system containing normal cells, but not in one containing cancer cells, there is the possibility of growth controlling substances flowing from cell to cell. Moreover, this electrical test for cell intercommunication could be used as a simple diagnostic test for cancer.

In the second paper, Loewenstein and Penn answer the question of whether poor intercellular communication is a feature of uncontrolled growth or growth in general. In regenerating liver, the cells grow as fast as any of the liver cancers studied and yet they have normal ionic communication, in striking contrast to liver cancer cells. Thus poor cell intercommunication is not a characteristic feature of growing cells. In wounded urodele skin the situation is more complex. Intact cells bordering cells wounded by a cut, and dying, seal themselves off from the exterior. Within 30 minutes of the cells of the two adjacent borders making contact at wound closure normal cellular communication is re-established and at this time contact inhibition stops cell growth and movement. It is, however, too early to say whether these two processes are causally related. As Loewenstein warns, it may be a gross over-simplification to suggest that contact inhibition is a single simple process resulting from the transmittance of a simple chemical signal. These experiments do nevertheless suggest that normal growth and differentiation of tissues depend on a flow of material from the interior of one cell to that of another.

\section{Pipelines, Bacteria and Manganese \\ from a Correspondent in Microbiology}

THERE are several reports of micro-organisms which can oxidize soluble manganous salts with the attendant formation of insoluble manganic deposits, but no report is more fascinating or thorough than a series of papers just published by P. A. Tyler and K. C. Marshall. They have investigated manganese accretion in pipeline installations of the Hydro-Electric Commission of Tasmania-a process which has serious consequences for power output (Antonie van Leeuwenhoek, $J$. Microbiol. Serol., 33, 171; 1967). Pipelines carrying water from Lake King William accumulate deposits up to $7 \mathrm{~mm}$ thick in 6-12 months, whereas in Great Lake pipelines only very thin deposits are formed. To facilitate the study a large scale perfusion apparatus was constructed to simulate conditions in the pipelines. The results from this apparatus were in full agreement with field observations. The role of microorganisms in the transformation of manganese was demonstrated by heat or chemical treatment of the waters, which completely arrested the process. It has emerged from these studies that Great Lake water 